\title{
Um framework para criação de jogos voltados para o ensino de lógica de programação
}

\author{
Tainá Medeiros ${ }^{1}$, Pedrina Brasil ${ }^{1}$, Eduardo Aranha ${ }^{1}$ \\ ${ }^{1}$ Programa de Pós-Graduação em Sistemas Computacionais (PPgSC) - Universidade \\ Federal do Rio Grande do Norte (UFRN) - Caixa Postal 1524 - Campus Universitário \\ Lagoa Nova - CEP 59072-970 - Natal - RN - Brasil \\ tainamedeiroseppgsc.ufrn.br, pedrinabrasilegmail.com, \\ eduardoaranha@dimap.ufrn.br
}

\begin{abstract}
Recently digital games have been used as aid to the transmission of knowledge tool, allowing disseminate content more quickly. Using this strategy to disseminate the development of logical reasoning to children the basic level can be the motivating gear that helps in the learning process for any area. In this context, this paper presents a framework for creating games aimed at teaching logic programming, showcasing the design, development through the integration of visual programming environment blockly scenarios created in HTML5.
\end{abstract}

Resumo. Recentemente os jogos digitais vêm sendo utilizados como ferramenta de auxilio à transmissão de conhecimento, permitindo difundir o conteúdo mais rapidamente. Utilizar essa estratégia para disseminar o desenvolvimento do raciocínio lógico para crianças do nível básico pode ser a engrenagem motivadora que ajuda no processo de aprendizagem para qualquer área. Neste contexto, este artigo apresenta um framework para criação de jogos voltados para o ensino de lógica de programação, apresentando a concepção, desenvolvimento através da integração do ambiente visual de programação blockly com cenários criados em HTML5.

\section{Introdução}

Por estimular o pensamento lógico, a criatividade e a capacidade de resolução de problemas, o estudo da programação vem sendo incentivado por diversas iniciativas internacionais, como a Code.org. Alguns especialistas discutem as vantagens de ensinar código a crianças, e defende o ensino da ciência da computação ao lado de outros cursos elementares, como matemática, biologia, física e química (Code.org, 2013).

Com a popularização dos computadores, tablets e smartphones, as crianças tendem a estar em contato com esses tipos de equipamentos a partir de seus primeiros anos de vida. Eles aprendem rápido como usá-los, mas raramente aprendem como eles funcionam. Há uma crescente ideia entre os educadores que defendem que esta lacuna precisa ser preenchida ensinando-se programação às crianças (Giroto, 2014).

A grande questão é que aprender a codificar não é uma fácil tarefa, especialmente para as crianças. E montar uma infraestrutura de aulas de programação nas escolas é bastante custosa e difícil. Nessa questão, as tecnologias digitais podem ser importantes aliadas, especialmente os jogos digitais, que inserem o estudante em 
cenários lúdicos que muitas vezes simulam problemas reais, sendo assim recursos mais atrativos para os estudantes. Segundo Medeiros (2013), a proposta de utilizar jogos digitais para o ensino de programação deve ser focada no ensino médio.

De fato, a Sociedade Brasileira de Computação (SBC) entende que os conceitos da Computação devem ser ensinados a partir do ensino básico e incentivam ações dessa natureza, na premissa de que essa área apresente princípios e habilidades que, se trabalhados com os estudantes desde cedo, podem contribuir para o exercício da lógica e resolução de problemas, assim como fomentar o interesse pela área, aumentando o número de profissionais no país (Melo, et.al, 2013).

Visando contribuir para o ensino de programação nas escolas do ensino básico, de uma forma contextualizada e divertida, este artigo apresenta um framework que facilita o desenvolvimento de jogos que ensinem lógica de programação.

\section{Metodologia e ferramentas utilizadas}

Este trabalho foi realizado a partir de uma revisão na literatura e na Internet sobre os jogos produzidos voltados para o ensino de programação. Baseado nessas informações, foi proposto um framework para facilitar o desenvolvimento de jogos deste tipo, fazendo uso do Blockly, um ambiente implementado em HTML5 para programação visual.

De fato, o Blockly em si não é uma plataforma educacional. Ele é um editor que podem ser utilizados como parte de uma plataforma educacional, ou como parte de um conjunto de negócios ou como parte de um sistema de jogos. A sua escolha se deu pela simplicidade e potencial de extensão da ferramenta.

\section{Framework para criação de jogos voltados para o ensino de lógica de programação}

Esta seção descreve um framework projetado para facilitar o desenvolvimento de jogos em HTML5 que ensinam lógica de programação através do editor Blockly. Os jogos criados através deste framework possuem a estrutura mostrada na Figura 1, a qual possui três contêineres: game canvas; blockly editor; game mode selector.

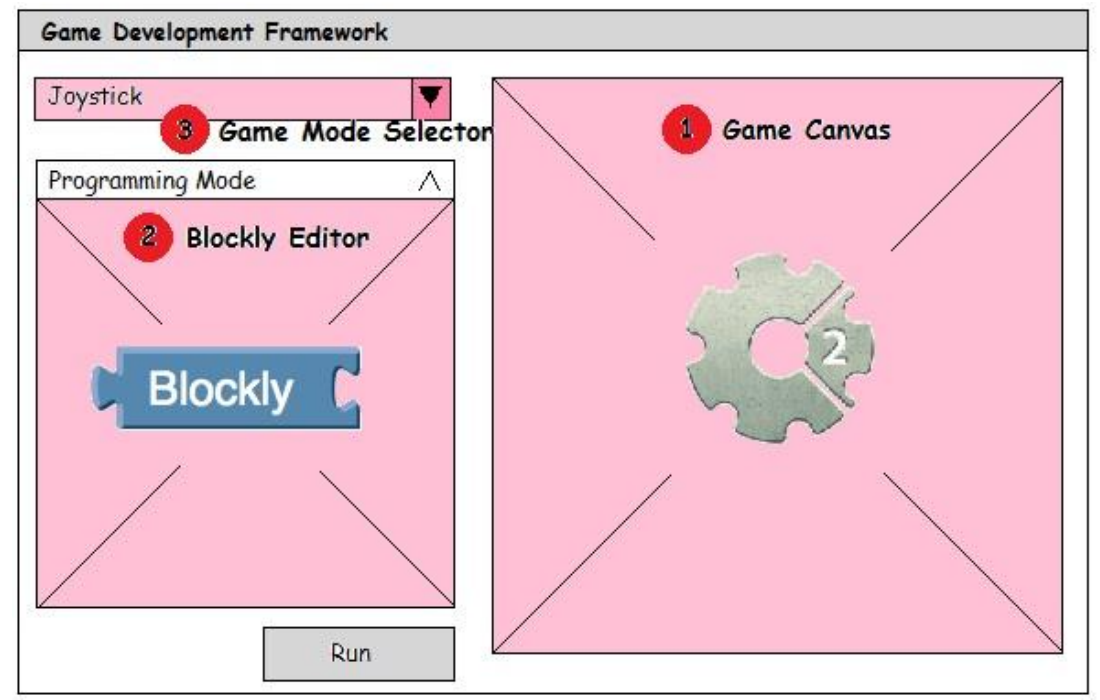

Figura 1. Game Development Framework 
No contêiner 1, Game Canvas, um jogo em HTML5 é dinamicamente carregado no espaço delimitado por ele. Da mesma forma ocorre com o Blockly, que é carregado no contêiner 2 - Blockly Editor. Já o contêiner 3 tem como objetivo permitir selecionar o modo de jogo (joystick ou blockly). Isto porque opcionalmente os jogos podem ser inicialmente jogados de forma convencional, através de teclas do teclado, mouse, etc., para que o jogador explore e entenda mais rapidamente o cenário do jogo, criando então uma estratégia que possa ser programada no Blockly e executada através do botão Run.

O jogo a ser carregado no contêiner 1 deve seguir certas regras para que sua integração ocorra com o Editor Blockly carregado no contêiner 2. A primeira delas é que o programador do jogo deve criar um arquivo Javascript contendo os blocos (comandos) que devem estar disponíveis no Editor Blockly, além daqueles que pertencem a lista padrão de comandos (estruturas condicionais, etc.). Estes blocos novos são específicos de cada jogo, pois representam operações sobre seus personagens e elementos do cenário (saltar, atirar, etc.).

A estrutura do código de criação dos novos blocos de programação (específicos do jogo) deve seguir a estrutura padrão de extensão do próprio Blockly. De fato, o framework é independente desta estrutura, visto que o framework apenas repassa informações sobre os blocos a serem executados do Blockly para o jogo, sem processar seu conteúdo.

Uma vez que o jogo e o Blockly encontram-se carregados e em execução, o jogador poderá programar os elementos do jogo utilizando o Editor Blockly. Para visualizar a execução de sua programação no jogo, o jogador irá acionar o botão Run. Com isso, o framework irá solicitar ao Editor Blockly que ele retorne a estrutura de blocos programados pelo jogador. Em seguida, será disparado o fluxo demonstrado na Figura 2.

Uma função chamada start() que deve ser implementada no jogo é executada com o objetivo de avisar ao jogo que existe uma programação a ser executada. De forma geral, esse método é responsável por solicitar ao framework, através da função executeNextBlock(), que seja executado o bloco (comando) da vez, segundo a programação criada pelo jogador. Executar o bloco da vez significa fazer o seu destaque visual (highlight) no Blockly Editor e invocar a função de execução associado a esse bloco. De acordo com o bloco em questão, essa função pode implementar desde estruturas condicionais e de laço (blocos do próprio Blockly) até ações específicas do jogo (blocos específicos do jogo).

No caso dos blocos específicos do jogo, estes possuem funções de execução que acionam movimentos e outros tipos de ações no jogo. Ao terminar a execução desta ação, o ciclo se repete para o próximo bloco a ser executado.

Finalizada a criação do jogo, ele deve ser exportado para HTML5. O Construct 2 se encarrega de gerar os artefatos de código e mídia necessários para execução do jogo. A Figura 3 apresenta uma visão do jogo em sua versão final, já integrado ao Blockly através do framework. 


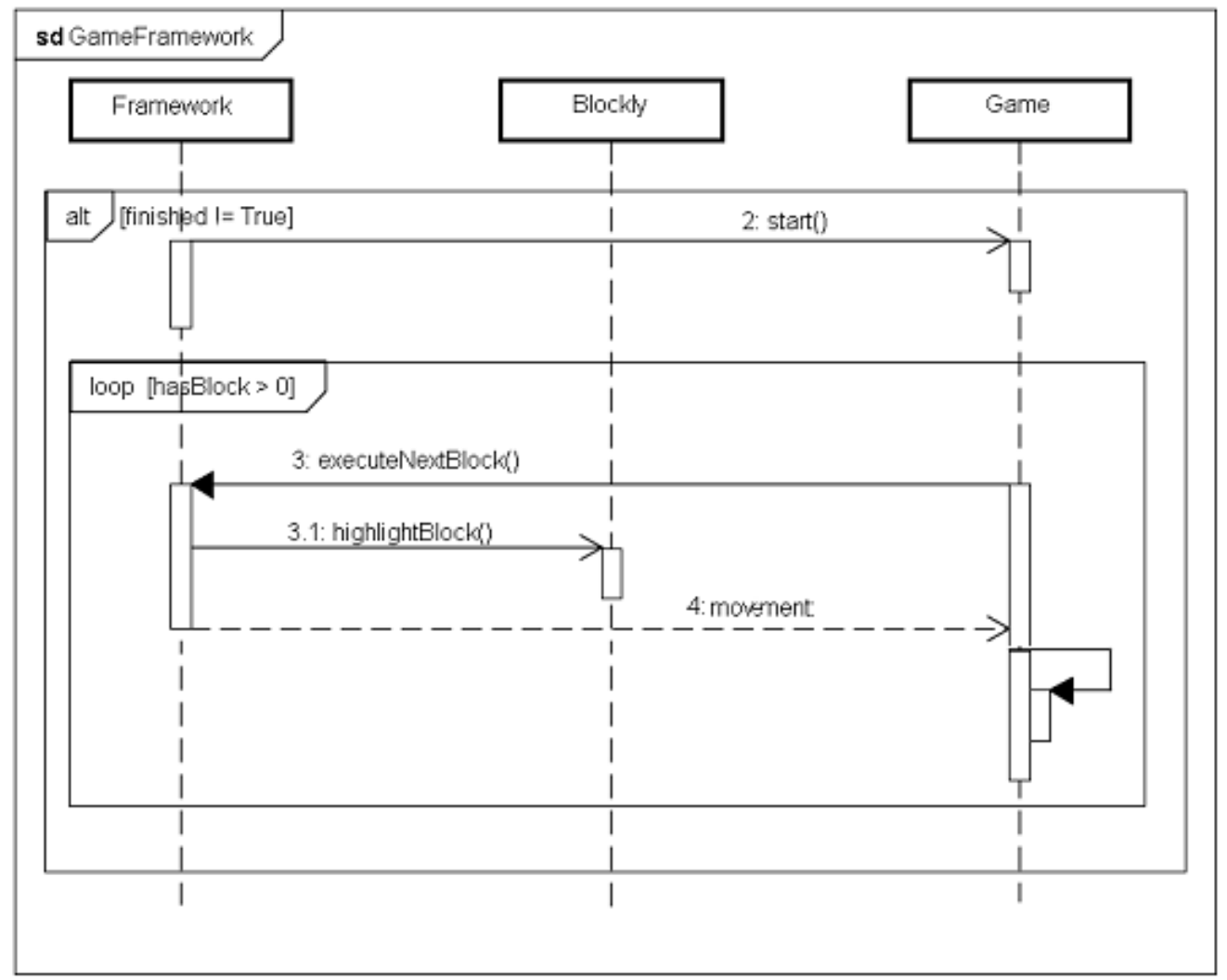

Figura 2. Execução da programação feita pelo jogador. ao Blockly através do framework

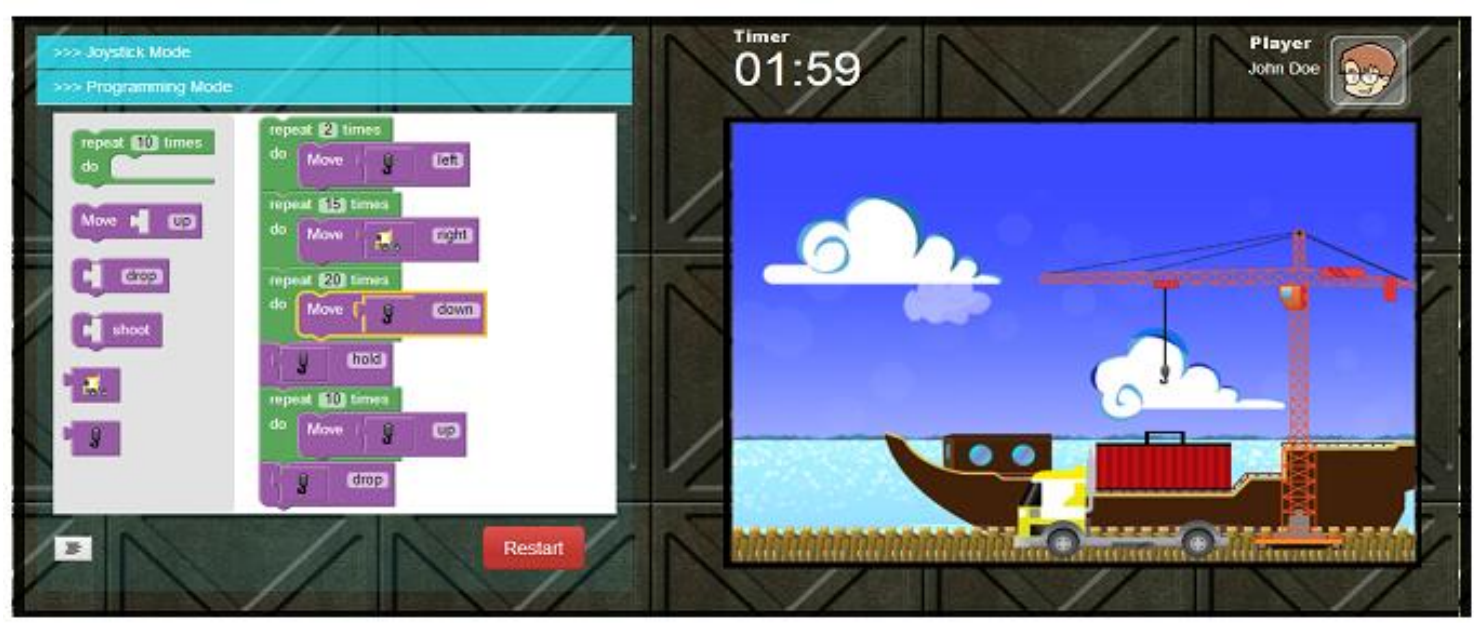

Figura 3. Exemplo de jogo desenvolvido integrado ao Blockly através do framework

\section{Trabalhos relacionados}

Alguns trabalhos são focados no ensino de programação baseadas em jogos. O Scratch, por exemplo, é um aplicativo que possibilita a criação de histórias, animações, jogos e outras produções, bem como o compartilhamento das criações na web. Já o Alice é um ambiente de programação 3D que facilita a criação de animações, jogos interativos, e vídeos que ensina conceitos de programação orientada a objetos. 
Porém, essas abordagens incentivam o estudo de programação enquanto o aluno está no desenvolvimento do jogo e não necessariamente o jogo possuir desafios de lógica de programação durante sua execução. Da forma que essas ferramentas tratam o ensino de programação, o aluno precisará de um certo nível de conhecimento sobre lógica de programação para começar a fazer os jogos.

Já outros trabalhos produziram jogos que ensinam lógica de programação. Entre eles podemos citar o Light-bot e Code Hunt. Nenhum desses trabalhos, porém, trazem meios que facilitem o desenvolvimento de novos jogos voltados para o ensino de programação como o aqui proposto. Através do framework podem ser desenvolvidos diferentes cenários de jogos, com que seus objetos passíveis de programação sejam manipulados através de uma lógica programada no Blockly Editor, criado e personalizado para aquele determinado momento do desafio no jogo.

\section{Conclusões e trabalhos futuros}

Este trabalho apresentou um framework para desenvolvimento de jogos digitais voltados para o ensino de lógica de programação. Os jogos produzidos precisam ser em HTML5 para sua integração com o Blockly Editor, podendo assim serem rodados na Web ou em plataformas móveis.

Como trabalho futuro, pretende-se desenvolver jogos com uma maior estrutura e qualidade, onde serão inseridos pequenos desafios durante sua execução, de acordo com a estrutura do framework proposto. Dessa forma o jogo será mais atrativo e completo, abordando diferentes aspectos a serem trabalhados em termos de lógica de programação.

\section{Agradecimentos}

Os autores agradecem a Coordenação de Aperfeiçoamento de Pessoal de Nível Superior (CAPES) pelo suporte parcial a esta pesquisa, ao Instituto Nacional de Engenharia de Software (INES), ao conselho Nacional de Desenvolvimento Científico e Tecnológico (CNPq), ao PROEXT MEC/SESu, e em especial ao Programa de Pós-graduação em Sistemas Computacionais PPgSC/UFRN, por toda infraestrutura oferecida.

\section{Referências}

Giroto , M. (2014), "Escola brasileira ensina programação para crianças”, Disponível em: < https:/queminova.catracalivre.com.br/2014/05/25/escola-brasileira-ensinaprogramacao-para-criancas/> . Acesso em: 10 jun. 2014.

Medeiros, T. J.; Silva, T. R.; Aranha, E. H. S. (2013) "Ensino de programação utilizando jogos digitais: uma revisão sistemática da literatura”. In: Revista Novas Tecnologias na Educação - RENOTE, v.11, n.3.

Melo, L. De. A.; Costa, T. K. De. L. E Batista, A. C. D. (2013), "Pense bem: proposta e desenvolvimento de jogo digital para ensino de computação na educação básica". In: XXIV Simpósio Brasileiro de Informática na Educação - SBIE.

The Code.org (2013), "Every student in every school should have theopportunity to learn computer science.", Disponível em: < http://code.org.>. Acesso em: 5 fev. 2014. 